\title{
USO DE PODCAST NO ENSINO DE LÍNGUA INGLESA: UM ESTUDO DE CASO
}

\author{
Susana Cristina dos Reis é Professora Adjunto 1, no Curso de Letras/UFSM/NTE; Pesquisadora e Líder do Grupo de pesquisa - \\ Núcleo de Pesquisa, Ensino e Aprendizagem de Línguas a Distância (NuPEAD). \\ E-mail: suzireis@nte.ufsm.br
}

Adilson Fernandes Gomes é aluno IC voluntário, integrante do NuPEAD.

E-mail: Adilson.fernandesgomes@gmail.com

Anderson José Machado Linck é aluno IC voluntário, integrante do NuPEAD.

E-mail: Anderson-linck@live.com

\section{RESUMO}

Pesquisas na área de Ensino de Línguas Mediado por Computador têm enfatizado a necessidade da produção de materiais didáticos apropriados para os diferentes contextos de interação que podem ser mediados por tecnologias educacionais (Reis, 2010. Considerando a necessidade de elaborar material didático para o ensino do Inglês como língua estrangeira, este artigo analisa uma proposta de desenvolvimento de material didático complementar para um curso de Inglês, usando a tecnologia podcast. Para desenvolver essa pesquisa, dados foram coletados durante a aplicação de um curso de inglês de extensão na universidade. Os resultados sugerem que o podcast é uma ferramenta digital com grande potencial para o desenvolvimento de atividades orais, uma vez que possibilita praticar o uso da língua inglesa por meio da ferramenta podcast, sem exigir alto nível de letramento digital por parte de seus usuários.

\begin{abstract}
Researches in the area of Computer Assisted Language Learning have emphasized the need to produce appropriate teaching materials to the different contexts of interaction that may be mediated by educational technologies (Reis, 2010). Considering the necessity of creating digital learning materials for Teaching English as a Foreign Language, this article aims to analyze a proposal to developing complementary teaching materials using the digital technology podcast. To do this research, the data were collected during the application of an English as a Foreign Language course at university. The results suggest that podcast is a digital teaching tool with great potential to the development of EFL oral activities which may not require high level of digital literacy from its users.
\end{abstract}

\section{1) INTRODUÇÃ̃O}

A Internet, no processo de evolução tecnológica, tem ao longo dos anos aprimorado o seu uso e recursos (Paiva; Bohn, 2008). Na Web 1.0 $0^{\mathrm{i}}$, a interação dos usuários com o meio virtual privilegiava a pesquisa de informações, enquanto que, na Web 2.0, o usuário passa não apenas a produzir conteúdos, mas também a divulgar e consumir conhecimentos diversos.

Com o surgimento da Web 2.0, a geração Homo Zappiens (Veen; Vrakking, 2009) ou a geração de nativos digitais (Prensky, 2001), atua em uma cultura cibernética global, baseada na multimídia e na colaboração em rede, já que nasceu inserida no 
contexto digital (Idem, 2001). Com isso, o acesso aos mais diversos contextos interativos (redes sociais, blogs, wikis, chats, jogos online, e outros) permite que a geração de nativos digitais sinta prazer em usar tecnologias, editar conteúdos online e dominar novas formas de comunicação, para desenvolver a sua própria autonomia.

Os recursos da Internet 2.0 facilitam a pesquisa de informações, favorecem a comunicação e a colaboração em rede, com o objetivo de agilizar e transformar a interação virtual, segundo o desejo ou a necessidade do usuário (Veen; Vrakking, 2009). Tendo em vista essa geração de usuários e os novos contextos de interação, a produção de material didático (doravante $\mathrm{MD}^{\mathrm{ii}}$ ) de línguas estrangeiras tem se tornado um desafio, tanto para os professores que atuam em escolas quanto em universidades.

Sendo assim, para preparar materiais pedagógicos adequados a esses novos contextos, novos letramentos (Cope; Kalantzis, 2009) são exigidos, tanto dos professores que ensinam com ou por meio de tecnologias, quanto dos alunos que fazem uso desses recursos (Ribeiro, 2009; Valente, 2008).

A Internet possibilita a inserção de seus participantes em diferentes práticas sociais e discursivas, as quais também requerem um novo perfil de professor mediador de conhecimentos (Reis, 2010). Dessa maneira, o professor precisa assumir a real função de mediador e de colaborador das interações (Vygotsky, 2008) que acontecem no ciberespaço para gerar aprendizagem e, assim, suprir as necessidades dos alunos com novas formas de interação social e de aprendizagem.

$\mathrm{Na}$ área de ensino de línguas mediado por computador (EMC) ${ }^{\mathrm{iii}}$, a produção de materiais didáticos digitais $(\mathrm{MDD})^{\mathrm{iv}}$ ainda é um tema de interesse de investigação na agenda de pesquisa na área de Ensino de Línguas Mediado por Computador (Reis, 2010), considerando que estamos inseridos em um mundo globalizado, conectado por hipermídias que, cada vez mais, desafiam os professores a explorar novas maneiras de ensinar e de aprender uma Língua Estrangeira (LE).

Devido a isso, é urgente a realização de pesquisas que explorem a produção de MD, com uso de ferramentas digitais, que envolvam os alunos em atividades de produção, de consumo e de distribuição desses materiais (Meurer, 2005). Com o propósito de melhor utilizar os recursos da Internet no ensino de LE, dentro das investigações realizadas no Grupo de Pesquisa - Núcleo de Pesquisa, Ensino e Aprendizagem de Línguas Online $\left(\mathrm{NuPEAD}^{v}\right)$, nosso foco principal é investigar como diferentes tecnologias digitais podem ser utilizadas pedagogicamente no ensino de línguas estrangeira. Assim, neste artigo, apresentamos resultados de um estudo de caso realizado em um dos projetos em desenvolvimento no NuPEAD, buscando responder a seguinte pergunta de pesquisa: Como a tecnologia podcast pode ser explorada pedagogicamente em atividades de ensino de LE?

Para responder a esse questionamento, temos como objetivos: 1) relatar uma proposta de produção de MD usando o podcast como recurso complementar para o desenvolvimento da produção oral em Língua Inglesa (doravante LI); 2) analisar cada

Revista Escrita

Rua Marquês de São Vicente, 225 Gávea/RJ CEP 22453-900 Brasil

Ano 2012. Número 15. ISSN 1679-6888.

escrita@puc-rio.br 
etapa e os procedimentos realizados na elaboração desse MD e, por fim, 3) apresentar os resultados obtidos nessa investigação.

O artigo está organizado em quatro seções: a primeira realiza reflexões sobre a produção de MD e caracteriza a tecnologia podcast; a segunda descreve a metodologia; a terceira destaca a análise das etapas e discute os resultados obtidos; a quarta e última seção resume as considerações mais relevantes desta pesquisa.

\section{2) ETAPAS DE PRODUÇÃo DE MATERIAL DIDÁtICO: FOCO NA AUTONOMIA}

De acordo com Leffa (2008), a produção de MD é um trabalho que envolve uma sequência de atividades sistemáticas, que pode variar de acordo com a complexidade do instrumento de aprendizagem que se deseja produzir. Assim, para a produção de MD, o autor sugere que há quatro etapas essenciais, que são: análise; desenvolvimento; implementação e avaliação (Figura 1).

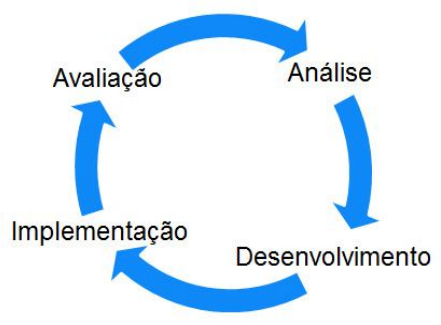
(2008).

Figura 1 - Elementos essenciais da produção de material didático. Fonte: Adaptado de Leffa

Para Leffa (2008, p. 16), a etapa de análise é "parte de um exame das necessidades dos alunos, incluindo seu nível de adiantamento e o que eles precisam aprender". O professor, ao pensar em desenvolver uma atividade, deve considerar, além de seus propósitos, o nível de conhecimento e as características pessoais de seus alunos. Esse conhecimento prévio, quando diagnosticado adequadamente, pode contribuir para o sucesso do desenvolvimento do MD e, consequentemente, resultar em aprendizagem (Idem, 2008).

Já a etapa desenvolvimento consiste em uma série de procedimentos que envolvem desde a motivação até a produção do MD (Leffa, 2008). Entre esses procedimentos, podemos citar: a definição do objetivo do MD; a definição da abordagem que orienta a construção desse material; a definição do conteúdo e das atividades que serão propostas, a definição dos recursos e do ordenamento das atividades, bem como as ações que serão tomadas em busca da motivação.

Na etapa da implementação, o cuidado pode variar de acordo com a presença de quem preparou o material. Assim, Leffa (2008) ressalta que há três situações básicas

\footnotetext{
Revista Escrita

Rua Marquês de São Vicente, 225 Gávea/RJ CEP 22453-900 Brasil

Ano 2012. Número 15. ISSN 1679-6888.

escrita@puc-rio.br
} 
que devem ser consideradas: 1) o material será usado pelo próprio professor? 2) o material será usado por outro professor? 3) o material será usado diretamente pelo aluno sem a presença de um professor?

A última situação, na perspectiva do autor, trata-se de uma situação difícil e que exige um grau maior de cuidado, pois há dois grandes desafios nesse processo de desenvolvimento. O primeiro consiste em ofertar ao aluno somente o necessário de informações, sem distorcer a complexidade do saber que ele precisa aprender; e, o segundo consiste em antecipar conteúdos, prevendo soluções para as possíveis respostas que surgirão, pois o professor não estará presente na execução da atividade (Leffa, 2008).

A avaliação é a última etapa da produção de MD. Nessa etapa, Leffa (2008, p. 40) destaca que a avaliação pode ser realizada de modo "informal" ou "formal". A primeira é realizada quando o próprio professor elabora, formula e reformula o material após a aplicação. A formal é realizada quando um grupo de professores elabora o material e a avaliação é realizada por meio de uma consultoria especializada. Geralmente, nessas situações, aplicam-se questionários ou entrevistas para essa tarefa. Em livros didáticos, pode-se fazer ainda um estudo piloto com os próprios alunos para avaliar o que deve permanecer como está, bem como modificar o que precisa ser melhorado no material.

A produção de MD, além de atender as etapas previstas, deve ser apropriada às necessidades do aluno e, ainda, deve promover a autonomia. $\mathrm{Na}$ perspectiva de Nicolaides e Fernandes (2008), a autonomia deve ser concebida como meta na educação, porém exige que o professor deixe de ser a figura central detentora do saber para possibilitar que o aluno tenha mais controle e responsabilidade no processo de aprendizagem.

Os conflitos que possam surgir em sala de aula, durante o uso do MD, devem ser levados em consideração, respeitando e estimulando a voz do aluno. Nessas condições, os alunos obterão mais controle do trabalho e, consequentemente, participarão mais ativamente do seu processo de aprendizagem. Assim, Nicolaides e Fernandes (2008, p. 47) consideram que os alunos estarão desenvolvendo "o aprender a aprender, suporte para um melhor resultado da aprendizagem não só na área de línguas, mas em diferentes campos do conhecimento".

$\mathrm{Na}$ perspectiva de Leffa (2008), as atividades desenvolvidas na Internet propiciam que o aluno, com autonomia, teste o seu conhecimento comparando com o dos colegas, pois há distribuição do conhecimento na rede. Tendo em vista investigar em que medida as etapas propostas por Leffa (Ibidem) podem ser utilizadas para a produção de MDD, elaboramos uma proposta de atividades que faz uso da tecnologia podcast. Na sequência descrevemos essa tecnologia.

\footnotetext{
Revista Escrita

Rua Marquês de São Vicente, 225 Gávea/RJ CEP 22453-900 Brasil

Ano 2012. Número 15. ISSN 1679-6888.
}

escrita@puc-rio.br 


\section{1) A TECNOLOGIA PODCAST COMO RECURSO PARA A PRODUÇÃO DE MATERIAL DIDÁTICO DIGITAL}

A tecnologia podcast é um recurso digital da web 2.0 que permite o download de arquivos em áudio em diferentes formatos. Pesquisas sobre o uso de podcasts na educação (Bottentuit Junior; Coutinho, 2007; Meng, 2005; Rosell-Aguiar, 2009), afirmam que o que diferencia o podcast de um simples arquivo de áudio disponível na Internet é o Real Simple Syndication 2.0 (RSS 2.0), pois é o feed RSS que proporciona ao usuário da Internet receber informações atualizadas sem a necessidade de visitar os sites um a um.

O termo podcast foi criado em 2004, após Adam Cury (apresentador da Music Television - MTV) e Dave Winer (produtor de software) desenvolverem um programa que permitia descarregar transmissões de rádios via Internet para os iPods. Assim, a denominação podcast originou-se da junção de iPod - aparelho da Apple que reproduz mp3 - e o termo Broadcast - transmissor e distribuidor de dados (Moura; Carvalho, 2006).

Para melhor compreender a terminologia que envolve o uso desse recurso da Internet são necessárias algumas definições. Para Rosell-Aguiar (2009), o podcast é qualquer arquivo na modalidade de áudio independente do contexto online em que são publicados, desde que alimentado por um feed RSS. Em estudos de Bottentuit Junior e Coutinho (2007), o podcast consiste no ambiente digital (site ou página) em que os arquivos de áudio são postados na web. Para esses autores (Ibidem), os arquivos de áudio são denominados episódios, podcasting é o ato de gravar ou divulgar o episódio e, o termo podcaster refere-se ao autor do episódio.

Tendo em vista fazer uso da tecnologia em aulas de LE, mais especificamente, na produção oral no ensino de LI, julgamos necessário seguir as etapas propostas por Leffa (2008) para orientar inicialmente a produção desse material.

\section{3) METODOLOGIA DESTA PESQUISA}

Iniciamos esta pesquisa seguindo as etapas de produção de $\mathrm{MD}$, proposta por Leffa (2008), para elaborarmos MDD de LI com uso da tecnologia podcast.

O contexto em que realizamos a testagem da proposta de MDD com uso da tecnologia podcast foi em um curso de extensão oferecido pelo Laboratório de Pesquisa e Ensino de Leitura e Redação, na UFSM, no segundo semestre de 2011. Esse curso de Inglês, ofertado para alunos em nível avançado em língua inglesa, visa desenvolver as quatro habilidades, trabalhando a produção e compreensão oral, bem como a leitura e escrita em LI.

$\mathrm{Na}$ testagem da proposta de MDD envolveram-se como participantes da pesquisa: a) os alunos do curso de extensão (acadêmicos de diferentes cursos de

\footnotetext{
Revista Escrita

Rua Marquês de São Vicente, 225 Gávea/RJ CEP 22453-900 Brasil

Ano 2012. Número 15. ISSN 1679-6888.

escrita@puc-rio.br
} 
graduação da UFSM); b) o professor-tutor (aluno em formação no curso de LetrasInglês); c) o professor-monitor (aluno em formação no curso de Letras-inglês que auxiliava nas atividades didáticas) e d) a supervisão pedagógica (professora do Curso de Letras).

Consideramos esta pesquisa um estudo de caso, porque nossa investigação realiza-se em um grupo específico, focalizando uma dada situação, sem a preocupação de descobrir uma verdade universal. O estudo de caso, segundo Marconi e Lakatos (2008, p. 108), é definido como o "estudo de determinados indivíduos, profissões, condições, instituições, grupos ou comunidades, com a finalidade de obter generalizações", abrangendo, assim, "o conjunto das atividades de um grupo social particular".

Para esta pesquisa utilizamos os seguintes instrumentos de coleta de dados: questionários semiestruturados (A e B) com perguntas abertas e fechadas; entrevista; relato escrito pelo professor-tutor do curso, anotações do professor-monitor, bem como as atividades propostas de produção oral (episódios publicados online).

Neste artigo sintetizamos dados quantitativos sobre o perfil dos participantes da pesquisa e citamos, na análise, dados qualitativos obtidos por meio da entrevista e dos relatos escritos tanto pelo professor-tutor quanto pelo professor-monitor. Na próxima seção, analisamos os dados encontrados a partir da metodologia implementada na pesquisa.

\section{4) ANÁLISE DAS ETAPAS DE PRODUÇÃO DO MATERIAL DIDÁTICO}

Para desenvolver a proposta de MDD com uso de podcast, seguimos inicialmente as quatro etapas propostas por Leffa (2008) e obtivemos os resultados que são descritos na sequência.

\section{1) ETAPA DE ANÁLISE}

De acordo com Leffa (Ibidem), na etapa de análise devemos prever procedimentos e instrumentos que forneçam dados sobre o aluno. Para obtermos esses dados, definimos procedimentos e instrumentos que seriam utilizados para a coleta de dados (ver Quadro 1). A partir dos dados coletados, constatamos que os alunos necessitavam de uma prática mais efetiva de produção oral, já que estavam em nível (pré) intermediário em LI.

Quadro 1 - Procedimentos e instrumentos na etapa de análise

\begin{tabular}{|l|l|}
\hline \multicolumn{1}{|c|}{ Procedimentos } & \multicolumn{1}{|c|}{ Instrumentos } \\
\hline $\begin{array}{l}\text { Levantamento das necessidades dos alunos, } \\
\text { realizada no início do curso. }\end{array}$ & $\begin{array}{l}\text { Questionário de levantamento de } \\
\text { necessidades e interesses dos alunos. }\end{array}$ \\
\hline
\end{tabular}

\footnotetext{
Revista Escrita

Rua Marquês de São Vicente, 225 Gávea/RJ CEP 22453-900 Brasil

Ano 2012. Número 15. ISSN 1679-6888.
}

escrita@puc-rio.br 


\begin{tabular}{|l|ll|}
\hline $\begin{array}{l}\text { Identificação do perfil dos alunos (linguístico } \\
\text { e tecnológico), por meio de questionamentos } \\
\text { escrito. }\end{array}$ & Questionário "A". \\
\hline $\begin{array}{l}\text { Identificação do nível de proficiência em } \\
\text { língua inglesa. }\end{array}$ & $\begin{array}{l}\text { Entrevista com participantes do } \\
\text { curso. }\end{array}$ \\
\hline $\begin{array}{l}\text { Levantamento dos conteúdos didáticos a } \\
\text { serem abordados no livro didático durante o } \\
\text { curso. }\end{array}$ & Livro didático em uso no curso de LI. \\
\hline
\end{tabular}

Com a finalidade de conhecer o perfil dos participantes deste estudo, foi aplicado o questionário (A). Os dados coletados permitiram identificar que os três acadêmicos eram de diferentes cursos de graduação da UFSM, sendo dois homens e uma mulher, na faixa etária de 19 a 23 anos.

Com relação ao grau de letramento digital dos participantes, os dados apontaram que todos faziam uso efetivo de ferramentas da Internet em suas atividades, pois acessavam a Internet diariamente em casa e/ou na UFSM; usavam Internet para se comunicar (e-mail, MSN e Orkut); para fins acadêmicos (pesquisas e elaborar trabalhos); para entretenimento (jogar, baixar músicas e filmes); para o trabalho profissional ( Vin $^{v i}$, Gtalk) e para fazer compras online. Os programas mais usados pelos participantes do curso eram Word, Excel, Power Point e Internet Explorer.

Os dados indicaram que os participantes demonstravam interesse em fazer uso de recursos da Internet para aprimorar a sua aprendizagem da LI, por meio de redes sociais, webquests, blogs, wikis, entre outros. Porém, nenhum aluno demonstrou conhecer ou ter utilizado a tecnologia podcast para essa finalidade, anteriormente a realização desta pesquisa.

Nesta etapa analisamos, ainda, o MD impresso que era utilizado nas aulas presenciais. Os conteúdos encontrados abordavam as seguintes temáticas: Problems \& Issues, Solutions, Travel and Leisure e Cinema ${ }^{\text {vii }}$ (Labler, 2011 ${ }^{\text {viii }}$. A partir da análise dos conteúdos e dos objetivos descritos em cada unidade do MD impresso, iniciamos a elaboração de uma proposta de MDD complementar, em que os alunos deveriam utilizar a tecnologia podcast para desenvolver a habilidade oral em LI.

Após a etapa de análise, iniciamos o planejamento dos procedimentos e das atividades previstas na etapa desenvolvimento (Leffa, 2008).

\section{2) ETAPA DE DESENVOLVIMENTO}

Com base em Leffa (Ibidem), a etapa de desenvolvimento, conforme mostra o Quadro 2, serve para definimos os objetivos, os procedimentos, a abordagem, os recursos, as atividades e o ordenamento dos passos a serem seguidos, bem como as ações que serão tomadas para favorecer a motivação, durante a produção do MD.

Quadro 2 - Procedimentos, atividades e definições na etapa de desenvolvimento

\footnotetext{
Revista Escrita

Rua Marquês de São Vicente, 225 Gávea/RJ CEP 22453-900 Brasil

Ano 2012. Número 15. ISSN 1679-6888.

escrita@puc-rio.br
} 


\begin{tabular}{|c|c|}
\hline Procedimentos & Atividades e definições \\
\hline Definição dos objetivos & $\begin{array}{l}\text { a) Argumentar sobre um problema vivenciado; } \\
\text { b) Expressar conhecimentos, apresentar soluções para } \\
\text { problemas; } \\
\text { c) Expressar preferências, convidar, aceitar ou recusar } \\
\text { convites, planejar ou descrever uma viagem; } \\
\text { d) Analisar, expressar suas preferências, avaliar, criticar } \\
\text { ou enfatizar um filme. }\end{array}$ \\
\hline Definição da abordagem & Abordagem baseada na tarefa (RAPAPORT, 2008) \\
\hline Definição do conteúdo & $\begin{array}{l}\text { a) Problems \& Issues; } \\
\text { b) Solutions; } \\
\text { c) Travel and Leisure; } \\
\text { d) Cinema. }\end{array}$ \\
\hline Definição da atividade & $\begin{array}{l}\text { Produção oral em língua inglesa por meio da tecnologia } \\
\text { podcast. }\end{array}$ \\
\hline Definição dos recursos & Livro didático, tecnologia podcast e a Internet \\
\hline $\begin{array}{l}\text { Ordenamento } \\
\text { atividades }\end{array}$ & $\begin{array}{l}\text { a) Abertura de uma conta podcast; } \\
\text { b) Elaboração e aplicação de tutoriais da abertura de conta } \\
\text { e de postagem de episódios no podcast; } \\
\text { c) Elaboração das atividades; } \\
\text { d) Aplicação das atividades e retirada de dúvidas; } \\
\text { e) Correção das atividades e feedbacks das propostas. }\end{array}$ \\
\hline Questão da motivação & $\begin{array}{l}\text { Ao introduzir um recurso da Internet (podcast), } \\
\text { observamos que as atividades despertaram o interesse e } \\
\text { motivação dos alunos, percebida pelos feedbacks } \\
\text { recebidos, comentários individuais em sala de aula, por } \\
\text { meio de e-mails. }\end{array}$ \\
\hline
\end{tabular}

Como sugere Leffa (2008), na etapa de desenvolvimento é importante definir com clareza os objetivos e a abordagem de ensino a serem utilizadas no MD. Neste trabalho, optamos pela abordagem baseada em tarefas, por concebermos que as imposições comunicativas das tarefas conduzem os alunos a utilizarem o seu conhecimento prévio, buscando informações complementares para produzirem um novo conhecimento (Rapaport, 2008).

Após essa organização inicial, notamos que quando trabalhamos com desenvolvimento de material didático com uso de tecnologias, a etapa de desenvolvimento não inclui a fase "construção do material digital", ou seja, no caso de produção de MDD, parece faltar uma etapa que prevê o desenvolvimento do material digital.

Como as atividades de produção oral por meio do podcast são no formato de áudio, para ilustrarmos as atividades propostas, transcrevemos com fidelidade a instrução falada no episódio original que foi postado como tarefa. As tarefas elaboradas para o MDD basearam-se na comunicação assíncrona e no uso colaborativo do podcast. Para Gomes et al (2011), o uso colaborativo de podcasts implica o próprio aluno 
elaborar, editar e postar o episódio, exigindo do participante interação e letramento para a execução da tarefa proposta.

$\mathrm{Na}$ sequência, apresentamos três exemplos de atividades elaboradas para o contexto digital com uso da tecnologia podcast.

\subsection{1) ATIVIDADES ELABORADAS PARA O MDD COM USO DA TECNOLOGIA PODCAST}

Ao elaborarmos as atividades de oralidade com uso de podcast, escolhemos alguns dos temas previstos no MD impresso para desenvolver atividades complementares em LI por meio de podcast. No site Podomatic ${ }^{i x}$, criamos as instruções dos episódios que foram disponibilizados aos alunos.

O episódio 1 refere-se a unidade 1 - Problems \& Issues. Na instrução dessa atividade, os alunos deveriam relatar um problema vivenciado, reportando quando, como e onde aconteceu o problema.

Exemplo 1 - Atividade 1 - Figura 2

Unit 1 - Activity 1 - Instruction of Episode 1": "Hello Everyone! This is the first virtual activity of comprehension and oral production. It will be related to the first unit seen so far. To do it, you are going to edit and post a short episode up to five minutes, narrating a problem involving personal life, university life or even at work that you face or have faced in life. If you have no positions to comment, maybe imaginary one, to better guide, you can answer the following topics: what, where, when, with whom or how. Good Luck!"

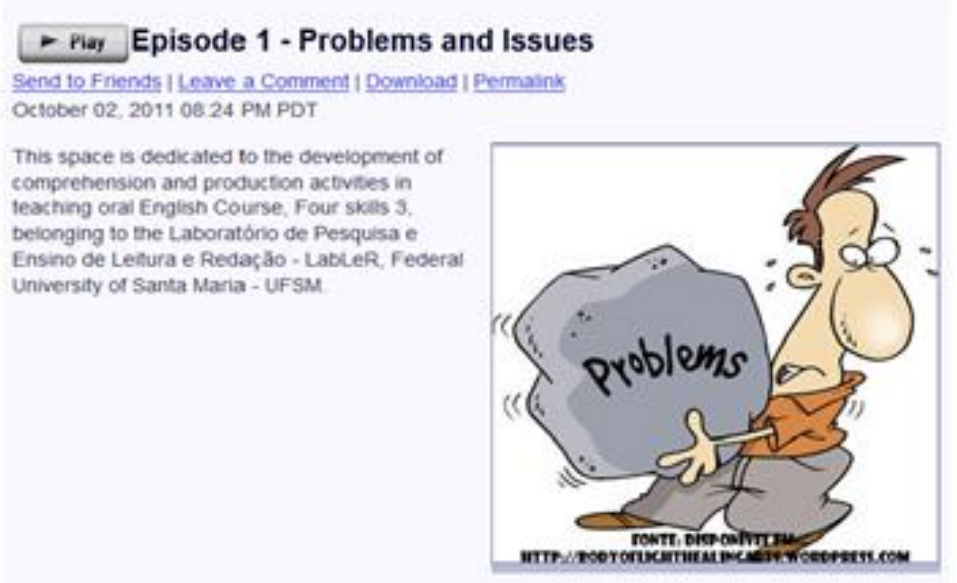

Figura 2 - Atividade 1 - Problems and Issues. Fonte: Disponível em: <http://fourskills.podomatic.com/>. Acesso em: 06 dez. 2011.

Já na unidade 2 - Solutions - o objetivo era expressar uma reação diante de um problema e indicar que aprendizagem foi obtida com essa experiência. Para esse 
propósito, os alunos, diante do vídeo London Metropolitan University: Students and workers lobby board of governors over cuts $^{x i}$, deveriam expressar seu conhecimento, opinando sobre o assunto tratado e, ainda, apresentar soluções possíveis, partindo do seu ponto de vista.

Exemplo 2 - Atividade 2 - Figura 3

Unit 2 - Activity 2 - Instruction of Episode $2^{\text {xii }}$ : - "Haven't you faced a similar situation in our university? As you can see this. It Is not just a developing country's problem, but a problem faced by students around the world. After watching this video that portrays a revolt by students of a British University. I would like you guys to think about it and give your opinion. Give a solution to this problem faced by many university students. What are your ideas for running a university for all? A university that suits our students for different degrees?"

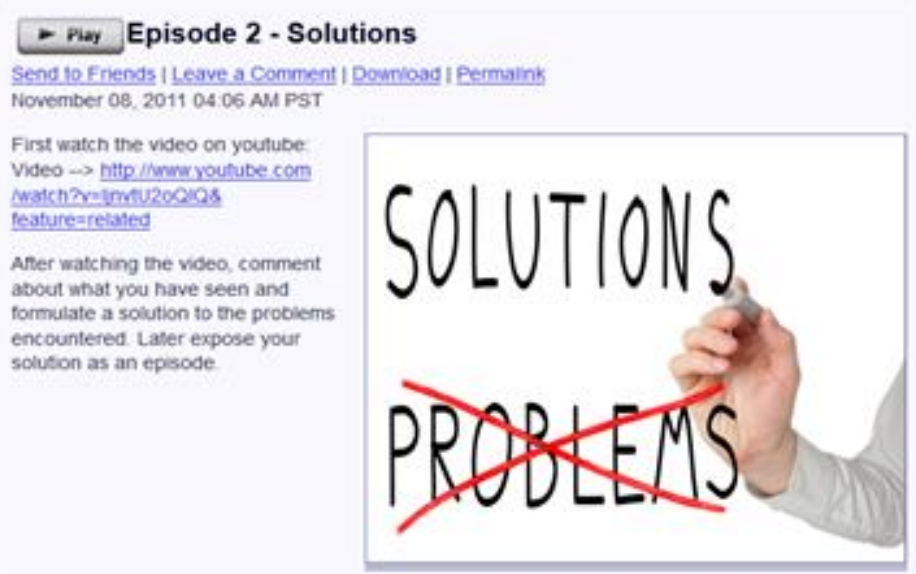

Figura 3 - Atividade 2 - Solutions. Fonte: Disponível em: <http://fourskills.podomatic.com/>. Acesso em: 06 dez. 2011.

Na unidade 4 - Cinema - os alunos na instrução do episódio receberam sugestões de trailers com diversos gêneros de filmes (Avatar ${ }^{x i i}$, Inception ${ }^{x i v}$, I am legend ${ }^{x v}$, Bad teacher ${ }^{x v i}$, Toy Story $3^{\text {xvii }}$ ), os quais eles poderiam assistir com o propósito de analisar, avaliar e criticar o filme, a partir de suas preferências pessoais.

Exemplo 4 - Atividade 4 - Figura 4

Unit 4 - Activity 4 - Instruction of Episode $3^{\text {xviii: }}$ "Hello Guys! It's Anderson here, and I have an activity for you. Pay attention, okay? You are going to watch a trailer of a movie proposed by the activity. Choose one of those or another movie trailer you might want to work with. You are going to create a 
synopsis of a movie using the knowledge you've got from previous activities and the movie language worked in class to develop it. Create an episode in response telling a friend about this movie using the synopsis which you created. Okay guys? Good Luck!"

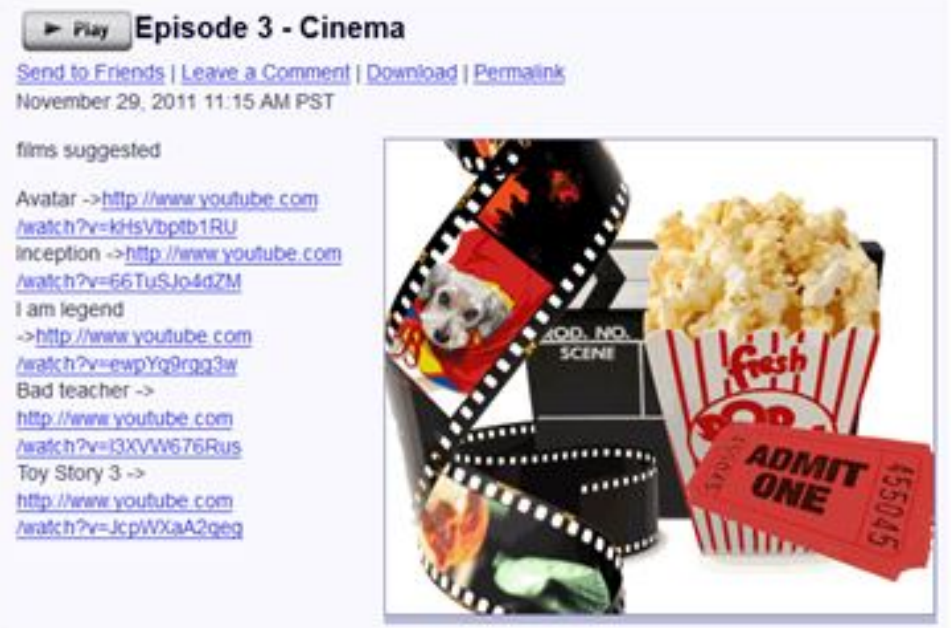

Figura 4 - Atividade 4 - Cinema. Fonte: Disponível em: <http://fourskills.podomatic.com/〉. Acesso em: 06 dez. 2011.

Após elaborarmos as tarefas, as atividades foram testadas pelos alunos do curso. A análise dos episódios produzidos demonstrou que os alunos conseguiram atingir o objetivo proposto nas instruções das atividades ${ }^{\text {xix }}$, ou seja, nos episódios identificamos os problemas, sejam estes reais ou imaginários e, também, a avaliação crítica de um filme. Para exemplificarmos as produções dos alunos, na sequência, organizamos três respostas dos episódios produzidos pelos alunos.

\section{Exemplo 1 - Produção do Aluno A - Episódio 1}

"A worker was wondering why he has to work every day, suddenly he called his boss and said he was quitting the job. However the boss fired him before he could leave, to his lucky he won... he won all way di bonus, this way he was rich, used all money to travel, but without being cheap. When realized he was without money and homeless in a strange land".

\section{Exemplo 2 - Produção do Aluno B - Episódio 1}

"Hi, I go to talk about my worst day. I'm a student and like the most students I have problems relation university and nice teacher...Uh, well. This bad day happened 29th April, at UFSM, but it started in my house, my problems is relation with engineer, because it's my course... well, last night I start...I started studied for the test, I study very, because I think this masteris very very difficult, so I studied... stay studied until 3 a.m. and I go to sleep,

\footnotetext{
Revista Escrita

Rua Marquês de São Vicente, 225 Gávea/RJ CEP 22453-900 Brasil

Ano 2012. Número 15. ISSN 1679-6888.

escrita@puc-rio.br
} 
because I was very tired, so in the morning I'm take the bus, but this niiiiiiiiiiiice bus broked,five go to university. I already with anger, because I would be late, so the repair of bus lated and I arrived twenty minutes later and my teacher didn't leave do to the test, so I lost the test, so take zero in the text maked the exam and reproved in this master. The date of is that in the day of the test was my birthday, so in this day was terrible".

Exemplo 3 - Produção do Aluno B - Episódio 4

"In 2007 a terrible vírus decimated the New York City, Robert Neville a survival scientist that is i-immune to the virus is looking for survivals and for a cure to disease caused by the virus for three years. He lives with his dog, but he is not completely alone. Human beings suffering mutations and they have to live in the darkness, because they can't take the sunlight, finally another survival heard his calls and together they will try to revert the virus effect and save the mankind. I am legend is started by Will Smith, Alice Braga and Charlie Tahan".

Neste artigo, nosso foco não é avaliar a fluência nas produções dos alunos, no entanto, verificamos se a produção oral estava coerente com o objetivo da tarefa. Embora seja possível observar a limitação do uso de vocabulário pela transcrição, bem como outros problemas gramaticais nos episódios, não avaliamos esses tópicos.

Para Bottentuit Junior e Coutinho (2007), quando utilizamos podcasts, criamos episódios que reportam conteúdos. Nessa proposta de MDD complementar os episódios agregam temas também trabalhados em sala de aula presencial, porém com outros problemas em foco.

Nos dados procuramos identificar a produção oral e a compreensão do aluno quanto ao tema proposto, bem como sua capacidade de formular soluções para os diferentes problemas apresentados, quando ele está em uma situação diferente de sala de aula, a distância e sem o auxílio do professor.

Os resultados obtidos no desenvolvimento e na implementação dessas atividades mostram que o uso de podcast como atividade complementar tem grande potencial como ferramenta para também gerenciar o acompanhamento do desenvolvimento da produção oral dos alunos, uma vez que, ao interagir nas situações de edição, produção e postagem de episódios online, os alunos podem refazer os episódios quantas vezes necessárias até chegar ao produto final desejado.

Sendo assim, é notável o potencial de uso dessa tecnologia para possibilitar a prática oral do conteúdo previamente estudado, visto que esse recurso não limita que as atividades de produção oral fiquem apenas restritas às interações realizadas em sala de aula presencial, como acontece, tradicionalmente, em cursos de Inglês como língua estrangeira (ou EFL) ${ }^{\mathrm{xx}}$ no Brasil.

Neste estudo, a prática da produção oral contou ainda com a prática online e a distância. Desta forma, as interações de aprendizagem ampliaram-se e possibilitaram

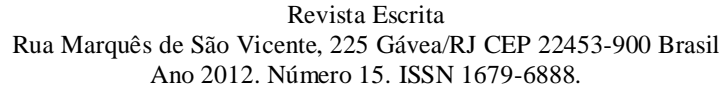


tanto ao aluno quanto ao professor interações que ultrapassam os limites da sala de aula. Além disso, o professor pode, por meio da tecnologia, elaborar comentários de feedback relacionado à performance do aluno, mesmo após o término da atividade.

$\mathrm{Na}$ sequência descrevemos a etapa de implementação, na perspectiva de Leffa (2008).

\section{3) ETAPA DE IMPLEMENTAÇÃO}

Nesta etapa, Leffa (Ibidem) sugere que devem ser previstas situações básicas de interação entre os autores e os usuários do material, ou seja, na elaboração do MDD preocupamo-nos em responder questões, tais como: 1) o MDD será utilizado pelo aluno em ambiente extraclasse ou em aula presencial? 2) O MDD será utilizado sem ou com a presença do professor-tutor? O Quadro 3 destaca um resumo dessas situações.

Quadro 3 - Atividades e situações na etapa de implementação

\begin{tabular}{|c|l|}
\hline Atividades & \multicolumn{1}{c|}{ Situações } \\
\hline 1,2 e 4 & $\begin{array}{l}\text { Os alunos realizaram as tarefas, em ambiente extraclasse, a distância, } \\
\text { sem a presença ou auxílio do professor-tutor. }\end{array}$ \\
\hline 3 & $\begin{array}{l}\text { Os alunos realizaram a atividade, em um primeiro momento, sem a } \\
\text { presença do professor e, em um segundo momento, em sala de aula } \\
\text { com a presença do professor-tutor. }\end{array}$ \\
\hline
\end{tabular}

É oportuno salientar que na etapa de implementação em que os alunos realizaram as tarefas sem a presença do professor-tutor (Atividades 1, 2 e 4), os participantes deveriam ter o conhecimento do uso da tecnologia podcast para que realizassem a atividade em um local de sua preferência. Por este motivo, elaboramos um tutorial explicativo sobre a tecnologia podcast.

A fim de garantir o uso adequado da tecnologia podcast, a implementação das produções orais dos episódios exigiu o planejamento de uma aula presencial em que os alunos do curso aprendessem a usar essa tecnologia. Desenvolver a fluência tecnológica do aluno, bem como o letramento quanto ao uso de tecnologias digitais pode ser uma maneira de facilitar a aprendizagem dos conteúdos linguísticos planejados na realização de tarefas de produção oral por meio de podcast, visto que ser letrado digitalmente, nessas situações, pode resultar em autonomia na aprendizagem de uma LE.

$\mathrm{Na}$ etapa de implementação, testamos, ainda, a possibilidade de combinar o acesso ao podcast extraclasse com a produção oral em sala de aula. Nesse propósito, solicitamos que os alunos acessassem uma tarefa no podcast (homework ${ }^{x x i}$ ), a qual seria posteriormente discutida na aula presencial.

Em vista disso, elaboramos a atividade 3 que envolveu o vídeo Travel and Leisure $^{\text {xxi }}$ (Homework - Listening). Nesse vídeo foram apresentadas informações sobre uma viagem para a Dinamarca, a qual serviu para oferecer subsídios linguísticos para a conversação oral em sala de aula presencial, com o propósito de ampliar o vocábulo e o

\footnotetext{
Revista Escrita

Rua Marquês de São Vicente, 225 Gávea/RJ CEP 22453-900 Brasil

Ano 2012. Número 15. ISSN 1679-6888.

escrita@puc-rio.br
} 
conhecimento prévio dos alunos sobre o tema viagens. Nessa atividade objetivamos levar os alunos a percepção de como se expressam preferências; como se faz, aceita ou recusa convites; como planejar ou descrever uma viagem.

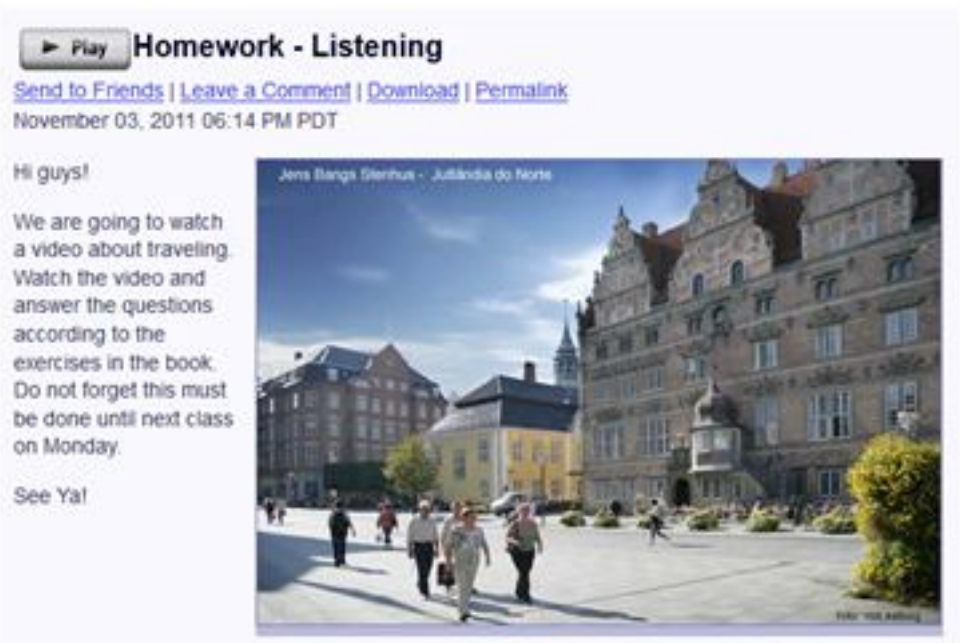

Figura 5 - Atividade 3 - Homework (Listening). Fonte: Disponível em<http://fourskills.podomatic.com/>. Acesso em: 06 dez. 2011.

\section{4) ETAPA AVALIAÇÃO}

A última etapa de elaboração da proposta de MDD complementar, buscou avaliar o desenvolvimento e a implementação das tarefas propostas. Nesta perspectiva, utilizamos os instrumentos descritos no Quadro 4.

Quadro 4 - Modos e instrumentos na etapa de avaliação do MDD

\begin{tabular}{|l|l|}
\hline \multicolumn{1}{|c|}{ Modos } & \multicolumn{1}{|c|}{ Instrumentos } \\
\hline A avaliação foi realizada de & $\begin{array}{l}\text { Avaliação formal foi realizada por meio do } \\
\text { Questionário "B". }\end{array}$ \\
\cline { 2 - 2 } $\begin{array}{l}\text { dois modos, os quais são: } \\
\text { formal e informal. }\end{array}$ & $\begin{array}{l}\text { A avaliação informal consiste em entrevista informal, } \\
\text { relatos do professor-tutor e o diário de anotação do } \\
\text { monitor. }\end{array}$ \\
\hline
\end{tabular}

Para avaliação utilizamos dois modos: formal e informal. Os dados obtidos na avaliação formal demonstraram a aceitação e os benefícios do uso da tecnologia podcast, bem como o desempenho dos alunos nas atividades de produção oral. Além disso, na percepção dos alunos, as atividades propostas favoreceram não apenas a produção oral, mas também a compreensão auditiva.

Os alunos informaram também que o fato das atividades via podcast estarem relacionadas aos conteúdos estudados em aula presencial favoreceu a execução das atividades extraclasse. 
Com relação ao uso da ferramenta podcast, os alunos consideram o uso desse recurso como positivo.

"senti um pouco de dificuldade para me orientar no site [podcast], mas depois consegui entender bem" (Aluno B);

"acredito que foram bem produtivas, em relação à produção oral e toda a preparação escrita feita, antes da gravação do episódio" (Aluno A);

"o podcast ajudou minha compreensão em relacionar os temas em aula, com temas da atualidade. Com isso, melhorei o entendimento do inglês, principalmente em leitura e entendimento oral" (Aluno C).

A avaliação informal consistiu em anotações e comentários do professor-tutor sobre o desenvolvimento e a eficácia da atividade realizada em sala de aula. Todas as observações realizadas na testagem piloto do MDD, sejam positivas ou negativas, geraram comentários em sala de aula e nos ajudaram a identificar as limitações ocorridas durante a pesquisa.

Esta pesquisa não tem a pretensão de apresentar uma verdade generalizável quanto à metodologia de produção oral que faz uso podcast no ensino de LE, mas de elaborar e testar atividades que façam uso desse recurso que é de fácil aplicabilidade e disponibilidade gratuita na Internet. Dessa forma, além de testarmos a tecnologia podcast em si, neste estudo de caso, também refletimos sobre o uso pedagógico desse recurso.

Portanto, nesta pesquisa, parece importante enfatizar que as etapas previstas por Leffa (2008) são aplicáveis também na produção de MDD, no entanto, observamos que elas podem ser ampliadas em função da inserção da tecnologia, tanto como recurso mediador da construção de tarefas/atividades quanto como recurso de interação entre os participantes do curso. Com isso, sugerimos que mais estudos sejam realizados e testados, visando proporcionar melhores subsídios a respeito da produção de material didático produzido para o contexto digital.

\section{5) CONSIDERAÇÕES FINAIS}

Os estudos do podcast para o ensino de LE são ainda recentes no Brasil, portanto, acreditamos que a descrição inicial da presente pesquisa pode contribuir com esse propósito. Dessa forma, consideramos que as etapas de MD propostas por Leffa (2008) são representativas e importantes para o professor que pretende orientar a elaboração de seu material didático, visando à motivação e à aprendizagem como fatores essenciais no ensino de LE.

Neste artigo, atingimos nosso objetivo de analisar as etapas de produção do MDD com base em pressupostos teóricos produzidos dentro da área da Linguística Aplicada, nesse caso, com base no estudo de Leffa (2008). Por outro lado, a análise

\footnotetext{
Revista Escrita

Rua Marquês de São Vicente, 225 Gávea/RJ CEP 22453-900 Brasil

Ano 2012. Número 15. ISSN 1679-6888.

escrita@puc-rio.br
} 
realizada proporcionou uma visão ampla sobre a complexidade e o desafio que envolve a produção de material didático para o contexto digital, tendo em vista as etapas consideradas neste estudo. Em se tratando de MDD sugerimos que novas etapas sejam adicionadas a esse modelo proposto.

Inicialmente, sugerimos manter a etapa de análise, pois ela é que dará subsídios para a construção das demais etapas. Como ressaltamos anteriormente ${ }^{\text {xxiii }}$, a etapa de desenvolvimento deveria ser entendida como etapa de planejamento da construção do $M D D$, seguida de uma etapa de produção do MDD por meio de uma tecnologia “ $x$ ”.

Além disso, pensamos que a inclusão da etapa testagem piloto do MDD é fundamental para verificarmos possíveis problemas, bem como para identificarmos o letramento dos usuários quanto ao uso da tecnologia em estudo. Após essas realizações, é possível incluir, ainda, a etapa Aplicação do $M D D$, visando à implementação e o redesign do MDD, caso fosse necessário. Fechando o ciclo de produção, segue a etapa de avaliação.

A investigação do uso da tecnologia podcast como recurso para gerar MDD ainda requer mais estudos, bem como a investigação de uma proposta de etapas de produção de MDD. Nossa intenção neste artigo não é divulgar algo acabado, e sim apresentar uma proposta de atividade em construção e que faz parte das investigações dos pesquisadores do NuPEAD.

\footnotetext{
${ }^{\mathrm{i}} \mathrm{Na}$ Web 1.0 não era permitido aos usuários o recurso da interação, tendo em vista que consideravam esses usuários uns simples espectadores. Na Web 2.0, a produção e a postagem dos conteúdos tornam-se uma rica fonte de transmissão de conhecimento e interação (PAIVA; BOHN, 2008);

${ }^{\text {ii }}$ Perspectiva de produção de material didático descrita por Leffa (2008);

iii Em inglês - CALL - Computer Assisted Language Learning;

iv Neste artigo, consideramos material didático digital aquele produzido para o ensino de línguas envolvendo ferramentas disponíveis na Internet;

${ }^{v}$ O Núcleo de Pesquisa, Ensino e Aprendizagem de Línguas a Distância (NUPEAD) tem como objetivo geral realizar investigações dentro das linhas de pesquisas que abordam os processos de Ensino e Aprendizagem de Línguas na modalidade a distância; o Letramento digital; Formação de professores para EAD e a Produção de material didático digital para ensino a distância.

${ }^{v i}$ Software livre;

vii Problemas e Questões; Soluções; Viagens e Lazer; Cinema;

viii Laboratório de Pesquisa e Ensino de Leitura e Redação (LABLER);

${ }^{\text {ix }}$ Plataforma para criar conta Podcast, disponível em: <http://www.podomatic.com>. Acesso em: 06 dez. 2011;

${ }^{\mathrm{x}}$ Unidade 1 - Atividade 1 - Instrução do episódio 1: "Olá a todos” Essa é a primeira atividade virtual de produção e compreensão oral. Essa unidade será relacionada com a primeira unidade vista até o momento. Para isso, você editará um episódio e postará um curto episódio de no máximo cinto minutos, narrando um problema envolvendo vida pessoal, vida universitária ou até mesmo no trabalho que você experencia ou experienciou em sua vida. Se você não tiver alguma posição quanto a isso, talvez imagine uma, para melhor guiá-lo nessa atividade, você pode responder os seguintes tópicos: qual, onde, quando, com quem ou como. Boa Sorte!"

${ }^{x i}$ Disponível em: <http://www.youtube.com/watch?v=ljnvtU2oQ1Q>. Acesso em: 06 dez. 2011;

xii Unidade 2 - Atividade 2 - Instrução do Episódio 2: Você já presenciou uma situação similar em nossa universidade? Como você pode ver, isso não é apenas um problema enfrentando por países em desenvolvimento, mas um problema presenciado por estudantes ao redor do mundo. Após assistir ao vídeo que retrata a revolta de estudantes de uma universidade Britânica, eu gostaria que vocês pensassem sobre essa situação e dessem a sua opinião. Apontem soluções para esse problema;

xiii Disponível em: <http://www.youtube.com/watch?v=kHsVbptb1RU>. Acesso em: 06 dez. 2011;
}

Revista Escrita

Rua Marquês de São Vicente, 225 Gávea/RJ CEP 22453-900 Brasil

Ano 2012. Número 15. ISSN 1679-6888.

escrita@puc-rio.br 
${ }^{\text {xiv }}$ Disponível em: <http://www.youtube.com/watch?v=66TuSJo4dZM>. Acesso em: 06 dez. 2011;

${ }^{\mathrm{xv}}$ Disponível em: <http://www.youtube.com/watch?v=ewpYq9rgg3w>. Acesso em: 06 dez. 2011;

${ }^{x v i}$ Disponível em: <http://www.youtube.com/watch?v=13XVW676Rus>. Acesso em: 06 dez. 2011;

xvii Disponível em: 〈http://www.youtube.com/watch?v=JcpWXaA2qeg>. Acesso em: 06 dez. 2011;

xviii Unidade 4 - Atividade 4 - Instrução do episódio 3: "Ola pessoal" Aqui é o Anderson quem fala, e eu tenho uma atividade para vocês. Prestem atenção, okay? Vocês irão assistir um trailer de um filme proposto pela atividade. Escolha um dos trailers abaixo ou escolha um que vocês queiram trabalhar. Vocês irão criar uma sinopse de um filme usando o conhecimento adquirido nas atividades anteriores envolvendo linguagem cinematográfica vista em aula para desenvolver sua resposta. Crie um episódio em resposta contando a um amigo sobre o filme escolhido usando a sinopse criada por você. Okay pessoal? Boa Sorte!

${ }^{\text {xix }}$ Ver exemplos das páginas 9, 10 e 11;

${ }^{\mathrm{xx}} \mathrm{EFL}$ - English as a foreign language;

xxi Tarefa para ser realizada em casa;

xxii Disponível em: <http://www.lonelyplanet.com/denmark/videos/sally-o-brien-copenhagen $\$$ ltvBF25E2D92E48F0B0>. Acesso em: 06 dez. 2011;

xxiii Ver 4.2 Etapa de desenvolvimento, página 9.

\section{REFERÊNCIAS BIBLIOGRÁFICAS}

BOtTentuit JUnioR, J. B.; COUTINHO, C. P. Podcast em Educação: um contributo para o estado da arte. In Barca, A.; Peralbo, M.; Porto, A.; Silva, B. D. \& Almeida L. (Eds.), Actas do IX Congresso Internacional Galego Português de Psicopedagogia. La Coruña: Universidade da Coruña. 2007. 837-846 p.

COPE, B; KALANTZIS, M. Multiliteracies: New Literacies, New Learning. Pedagogies: International Journal, v. 4, n. 3, p. 164-195, July 2009. Disponível em: <http://newlearningonline.com/files/2009/03/pedagogiesm-litsarticle1.pdf>. Acesso em: 18 jul. 2012.

GOMES, A. F.; DE SÁ, C. G.; FIALHO, V. R. Podcast: uma opção didática para o ensino de E/LE. In: $5^{\circ}$ CONGRESSO NACIONAL DE AMBIENTES HIPERMÍDIA DE APRENDIZAGEM, UCPEL, 2011. Disponível em: <http://wright.ava.ufsc.br/ alice/conahpa/anais/2011/papers/20.pdf>. Acesso em: 12 jan. 2012.

LABLER. Portal do Laboratório de Pesquisa e Ensino de Leitura e Redação. 2011. Disponível em: <http://w3.ufsm.br/labler/>. Acesso em: 28 dez. 2011.

LEFFA, V. J. "Como produzir materiais para o ensino de línguas". In: LEFFA, V. J. (org.). Produção de materiais de ensino: teoria e prática. 2. ed. rev. Pelotas: Educar, 2008. 15-41 p.

MARCONI, M. A.; LAKATOS, E. M. Fundamentos da metodologia científica. 6. ed. São Paulo: Atlas. 2008. 315 p.

MENG, P. Podcasting and vodcasting: a white paper. Definitions, discussions, andimplications. $2005 . \quad$ Disponível em: 
<http://www.wssa.net/WSSA/SocietyInfo/ProfessionalDev/Podcasting/Missouri_Podca sting_White_Paper.pdf>. Acesso em: 18 ago. 2012.

MEURER, J. L. "Gêneros textuais na análise crítica de Fairclough". In: MEURER, J. L.; BONINI, A; MOTTA-ROTH, D. (orgs.). Gêneros: teorias, métodos, debates. São Paulo: Parábola Editorial, 2005. 81-106 p.

MOURA, A; CARvalho, A. A. A. Podcast: potencialidades na educação. Rev. Prisma.com, n. 3, p. 88-110. 2006. Disponível em: <http://revistas.ua.pt/index.php/prismacom/article/viewFile/623/pdf>. Acesso em: 18 dez. 2011.

NICOLAIDES. C.; FERNANDES. V. "Autonomia: critérios para a escolha de material didático e suas implicações". In: LEFFA, V. J. (org.). Produção de materiais de ensino: teoria e prática. 2. ed. rev. Pelotas: Educar, 2008. 43-67 p.

PAIVA, V. L. M. O.; BOHN, V. C. R. O uso de tecnologias em aulas de LE. 2008. Disponível em: <http://www.veramenezes.com/paivabohn.pdf>. Acesso em: 20 jan. 2012.

PRENSKY, M. Digital Natives, Digital Immigrants. On the Horizon, MCB University Press, v. 9, n. 5, Oct. 2001. Disponível em: <http://www.marcprensky.com/writing/Prensky - Digital Natives, Digital Immigrants Part1.pdf>. Acesso em: 18 ago 2012.

RAPAPORT, R. Comunicação e tecnologia no ensino de línguas. Curitiba: Ibpex, 2008.

REIS, S. C. Do discurso à prática: textualização de pesquisas sobre o ensino de inglês mediado por computador. Tese apresentada ao Programa de Pós-Graduação em Letras, Área de Estudos Linguísticos, da Universidade Federal de Santa Maria, para obtenção do título de Doutor em Letras. Santa Maria, RS, Brasil, 2010.

RIBEIRO, A. E. Letramento digital: um tema em gêneros efêmeros. Rev. ABRALIN, v. 8, n. 1, p. 15-38, jan./jun. 2009.

ROSELL-AGUILAR, F. "Podcasting for language learning: re-examining the potential". In: LOMICKA, L.; LORD, G. (org.). The next generation: social networking and online collaboration in foreign language learning. 8 ed. Texas, USA: Editora CALICO, 2009, 13-34 p.

VALENTE, J. A. As tecnologias digitais e os diferentes letramentos. Rev. Pátio, Porto Alegre, ano 11, n. 44, p. 13-15, nov. 2007/jan. 2008.

VEEN, W.; VRAKKING, B. Homo zappiens: educando na era digital. Porto Alegre: Artmed, 2009.

VYGOTSKY, L. S. Pensamento e linguagem. 4. ed. São Paulo: Martins Fonte, 2008.

$$
\begin{gathered}
\text { Revista Escrita } \\
\text { Rua Marquês de São Vicente, 225 Gávea/RJ CEP 22453-900 Brasil } \\
\text { Ano 2012. Número 15. ISSN 1679-6888. } \\
\text { escrita@ @ puc-rio.br }
\end{gathered}
$$

